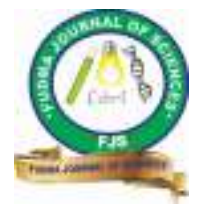

FUDMA Journal of Sciences (FJS)

ISSN online: $2616-1370$

ISSN print: 2645 - 2944

Vol. 4 No. 3, September, 2020, pp $142-147$

DOI: https://doi.org/10.33003/fjs-2020-0403-201

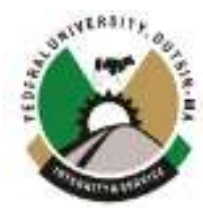

\title{
PHOTOLUMINESCENCE OBSERVATIONS OF DONOR-ACCEPTOR EMISSION IN MILLED Cd0.3Zn0.7Se
} NANOCRYSTALS

\author{
I. M. Bagudo ${ }^{1,2}$ and A. Tanimu ${ }^{1}$ \\ ${ }^{1}$ Department of Physics, Umaru Musa Yar'adua University, Katsina State, Nigeria \\ ${ }^{2}$ Ibrahim Shehu Shema Centre for Renewable Energy and Research, Umaru Musa Yar'adua University, Katsina State, Nigeria \\ ${ }^{*}$ Corresponding Author's Email: ibrahim.bagudo@umyu.edu.ng
}

\begin{abstract}
Defects and impurities that arise during material synthesis are detrimental to device performance. Hence, an effective characterization tool is fundamental to effectively quantify and understand the origin of such defects. In this paper, we examine photoluminescence spectra (PL) from $(650-900) \mathrm{nm}$ of mechanically alloyed $\mathrm{Cd}_{0.3 \mathrm{Zn} 0.7} \mathrm{Se}$ nanocrystals and observe three prominent emission peaks $(1.4,1.8$, and 1.54$) \mathrm{eV}$. The peaks were pinned at a fixed position despite a decrease in crystallites size which ought to increase the energy bandgap. The intensity of the peaks increases with milling time due to longer milling time which gives rise to a higher density of intrinsic defects. This was attributed to continuous deformations from the milling process. The formation energies of acceptor and donor defects remain constant to the conduction and valance band edge.
\end{abstract}

Keywords: Mechanical alloying, Photoluminescence spectra (PL), Donor-acceptor pairs (DAP), defects.

\section{INTRODUCTION}

Alloyed CdZnSe nanocrystal has been employed for the fabrication of light-emitting devices superior with spectral properties. The bottle-neck surrounding its wider applications in areas such as absorber layers in solar cells, sensors, and biological labeling is the presence of non-radiative decay channels associated with surface state defects, intrinsic point defects, and other stoichiometric defects.

The presence of deep-level emission (DLE) in undoped CdZnSe involves a hole of the intrinsic point defects such as vacancies, interstitials, and antisites. It is well known that point defects affect the electrical and optical properties of $\mathrm{CdZnSe}$. There have been limited reports on the DL emission in $\mathrm{CdZnSe}$ nanocrystals. (Bhattacharyya et al., 2009) observed a broad DL emission from $590-750 \mathrm{~nm}(2.10$ to $1.65 \mathrm{eV})$ centered at $650 \mathrm{~nm}$ $(1.839 \mathrm{eV})$ which was attributed to radiative recombination involving donor-acceptor pairs (DAP). Zhang et al. (Zhang \& Hark, 2000), reported DL emission from (1.3 to $1.8 \mathrm{eV})$ in $\mathrm{Zn}_{\mathrm{x}} \mathrm{Cd}_{1-\mathrm{x}} \mathrm{Se}$ grown by organometallic-vapor-phase epitaxy (OMVPE). The DL emission originated from cation-vacancy related to stacking faults. In the same vein, $\mathrm{Zn}_{\mathrm{x}} \mathrm{Cd}_{1-\mathrm{x}} \mathrm{Se}$ grown by metal-organic chemical vapor deposition (MOCVD) on InP substrate, produced a broad DL emission observed from (1.35$1.9 \mathrm{eV})$. The origin of DLE was also attributed to cation-vacancy related complexes (Zhang et al., 1998). However, Burger et al. (Burger \& Roth, 1984), reported DLE at $0.49 \mathrm{eV}$ below the conduction band in $\mathrm{Zn}_{0.3} \mathrm{Cd}_{0.7} \mathrm{Se}$ from space charge density analysis. They attributed the observed defect level to interstitial $\mathrm{Cu}$ - and a $\mathrm{V}_{\mathrm{Cd}}$ pair. Similarly, Al-Bassam et al. reported an additional DLE in $\mathrm{Zn}_{0.3} \mathrm{Cd}_{0.7} \mathrm{Se}$ crystal at (1.1-1.15) eV located in the middle of the bandgap. It was associated with an electron trap (Al-Bassam \& Elani, 2013).

Photoluminescence spectroscopy (PL) measurements offer the opportunity to study defect states in a semiconductor material. PL emissions at longer wavelengths are usually associated with defect centers. An electron excited from the ground states becomes localized at mid-gap impurity centers. The excess energy is non-radiatively transmitted in the form of heat (vibrations) to the crystal lattice after the time $\left(t_{n}\right)$; the process can lead to the generation of lattice defects. The low-energy component of the spectra consists of various emissions from structural defects.

In this work, we aim to reveal for the first time the defect characteristics of milled $\mathrm{Cd}_{0.3} \mathrm{Zn}_{0.7}$ Se nanocrystals at $(625 \mathrm{~nm}$ to 900)nm spectral window using photoluminescence spectroscopy analysis.

\section{MATERIALS AND METHOD}

The experimental procedure used to synthesize $\mathrm{Cd}_{0.3} \mathrm{Zn}_{0.7} \mathrm{Se}$ was similar to that reported earlier by (Muh'd et al., 2015). Three elemental constituents ( $\mathrm{Cd}, \mathrm{Zn}$, and $\mathrm{Se}$ ) purchased from (Alfa Aesar of $99.9 \%$ ) purity were sealed in a grinding jar made of stainless steel. The powder was thoroughly ground for 5, 10, and $20 \mathrm{~h}$ intervals using a PM100 (Retsch) at 300 revolutions per minute. One gram of the milled powder was dissolved in 5 $\mathrm{ml}$ of acetone for photoluminescence measurements using a Perkin-Elmer (LS-55) luminescence spectrophotometer located at Physics Department University Putra Malaysia.

\section{RESULTS AND DISCUSSION}




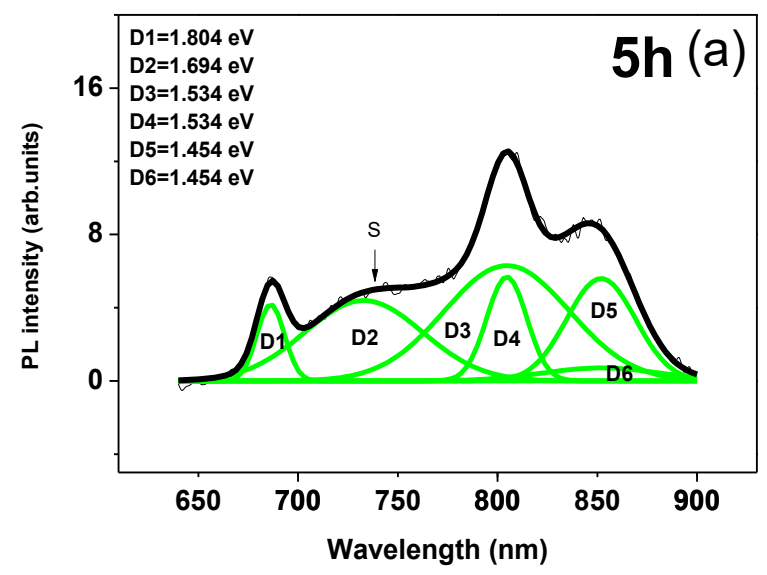

Figure $1(\mathrm{a}-\mathrm{c})$. Temporal evolutions of PL spectra at room temperature of $\mathrm{Cd}_{0.3} \mathrm{Zn}_{0.7}$ Se nanocrystal for a) 5 , b) 10 , and c) $20 \mathrm{~h}$. The multi-peak Gaussian fitted to the PL spectra consists of three prominent emission bands evolving over the milling time. The $\mathrm{S}$ with an arrow indicates a dislocation related band.

The PL spectrum of the $5 \mathrm{~h}$ milled nanocrystals powders is shown in Fig. 1(a) has six emission peaks labeled D1 to D6 (from high photon energy to low photon energy of the spectrum). The spectra of the milled samples were fitted with multiGaussian peaks; the fitting parameters are summarized in Table 1. In line with the Gaussian fitting results, the photon energies of these peaks related to D1 and D2 are 1.804 and $1.694 \mathrm{eV}$, respectively. Peaks D3 and D4 are of the same origin with a photon energy of $1.540 \mathrm{eV}$. Similarly, peaks D5 and D6 have a photon energy of $1.454 \mathrm{eV}$. The PL spectral bandwidths of peaks D1-D6 are 16, 70, 24, 73, 41, and $69 \mathrm{~nm}$, respectively.

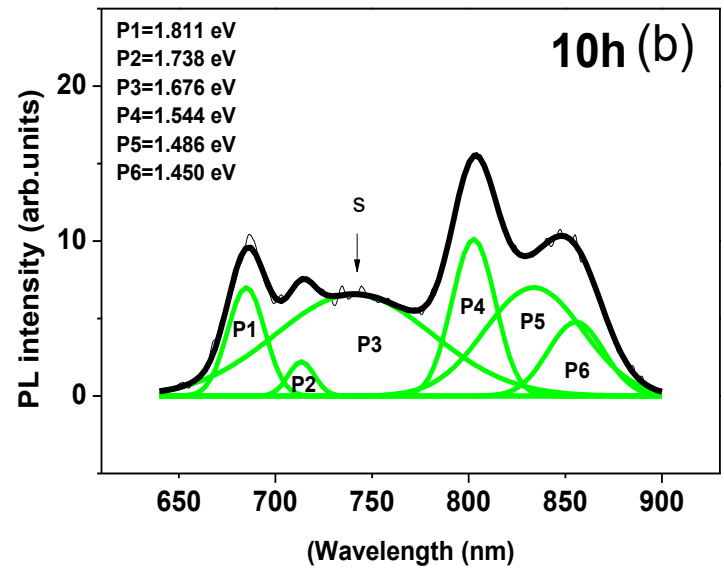

As shown in Fig.1 (b), the fitted PL peak energies of the $10 \mathrm{~h}$ milled sample are represented by P1, P2, P3, P4, P5, and P6 with corresponding photon energies of $1.811,1.738,1.676,1.544,1.486$, and $1.450 \mathrm{eV}$ and PL spectral bandwidths of 23 , $16,96,26,60$, and $34 \mathrm{~nm}$, respectively. 


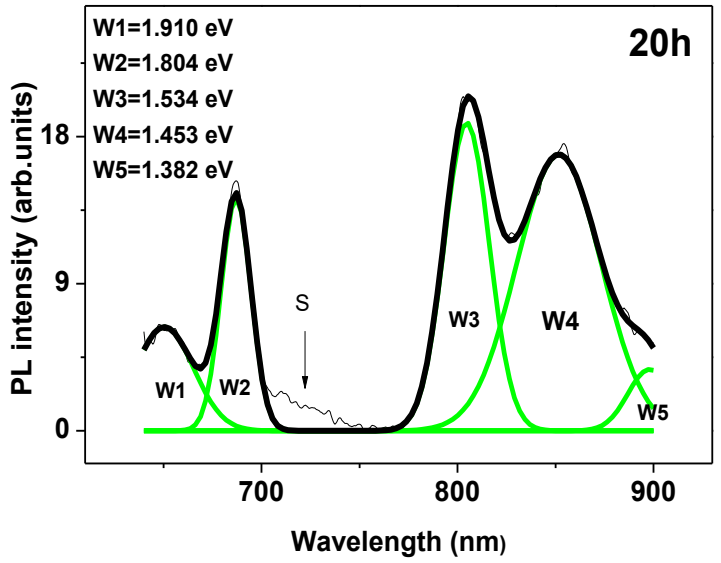

In Fig. 1 (C), the $20 \mathrm{~h}$ milled sample fitted photon energies are W1, W2, W3, W4, and W5 with corresponding photon energies of $1.910,1.804,1.539,1.454$, and $1.382 \mathrm{eV}$ and spectral bandwidths of $28,18,27,51$, and $12 \mathrm{~nm}$, respective

Table 1. Fitting parameters for $(5-20) h$ milled $\mathrm{Cd}_{0.3} \mathrm{Zn}_{0.7}$ Se powders.

\begin{tabular}{|c|c|c|c|c|c|}
\hline Peak No. 5h milled & Peak Assignment & Center Maximum(nm) & $\begin{array}{l}\text { Maximum } \\
\text { Height }\end{array}$ & FWHM & Peak energy $(\mathrm{eV})$ \\
\hline Peak 1 & D1 & 687 & 4.14 & 16.47 & 1.80 \\
\hline Peak 2 & D2 & 733 & 4.39 & 69.60 & 1.69 \\
\hline Peak 3 & D3 & 805 & 5.68 & 23.74 & 1.54 \\
\hline Peak 4 & D4 & 805 & 6.30 & 73.86 & 1.54 \\
\hline Peak 5 & D5 & 852 & 5.60 & 40.53 & 1.45 \\
\hline Peak 6 & D6 & 852 & 0.71 & 69.30 & 1.45 \\
\hline \multicolumn{6}{|l|}{ 10h milled } \\
\hline Peak 1 & $P 1$ & 685 & 7.00 & 22.60 & 1.81 \\
\hline Peak 2 & P2 & 714 & 2.21 & 15.93 & 1.74 \\
\hline Peak 3 & P3 & 740 & 6.56 & 95.77 & 1.68 \\
\hline Peak 4 & P4 & 803 & 10.11 & 26.41 & 1.54 \\
\hline Peak 5 & P5 & 834 & 6.99 & 59.82 & 1.50 \\
\hline Peak 6 & P6 & 855 & 4.77 & 34.15 & 1.45 \\
\hline \multicolumn{6}{|l|}{ 20h milled } \\
\hline Peak1 & W1 & 651 & 6.36 & 27.91 & 1.91 \\
\hline Peak2 & W2 & 687 & 14.26 & 18.12 & 1.80 \\
\hline
\end{tabular}




\begin{tabular}{|l|l|l|l|l|l|}
\hline Peak3 & W3 & 805 & 18.81 & 27.22 & 1.54 \\
\hline Peak4 & W4 & 853 & 16.90 & 50.68 & 1.45 \\
\hline Peak5 & W5 & 897 & 3.75 & 12.34 & 1.38 \\
\hline
\end{tabular}

In the PL spectra of all three samples, a band related to dislocation donated by (S) at approximately $1.7 \mathrm{eV}$ was observed. The integral intensity of this band exhibits approximately five-fold decrease after $20 \mathrm{~h}$ of milling. Dislocation-related emission peaks were observed in mechanically alloyed $\mathrm{ZnSe}$ and $\mathrm{ZnO}$ (Radoi et al., 2003, 2004). The fitted emission peaks in Fig. $1(\mathrm{a}-\mathrm{c})$ are dominated by deep defect level emission from $650-897 \mathrm{~nm}(1.38-1.91 \mathrm{eV})$. Similarly, deep-level emission (DL) was observed in ZnSe, $\mathrm{CdSe}$, and CdZnSe, as shown in Table 2. Such emissions are usually attributed to stacking faults and stoichiometric defects that include intrinsic point defects (vacancies and interstitials). An important mechanism for luminescence in semiconductors is the recombination between an electron trapped at one defect (donor) and a hole trapped at another defect (acceptor). A large concentration of vacancies and interstitial with different charge states $\left(\mathrm{V}_{\mathrm{Cd}}, \mathrm{V}_{\mathrm{Zn}}\right.$, and $\left.\mathrm{V}_{\mathrm{Se}}\right)$ are typically found in the milled samples. These defects generate additional localized energy levels within the bandgap and eventually recombine into donoracceptor pairs (DAPs).

Table 2. Energy position of defect centers and donor-acceptor pairs in $\mathrm{ZnSe}, \mathrm{CdSe}$, and CdZnSe.

\begin{tabular}{|c|c|c|c|}
\hline Material & Defect & Energy level (nm) & Ref. \\
\hline \multirow[t]{3}{*}{$\mathrm{ZnSe}$} & $\left(\mathrm{V}_{\mathrm{Zn}}-\mathrm{Zn}_{\mathrm{i}}\right)$ & 600 & (Rong \& Watkins, 1986) \\
\hline & & 800 & \\
\hline & $\mathrm{V}_{\mathrm{Zn}}$ & 720 & (Lee et al., 1980) \\
\hline \multirow{5}{*}{ 2007) } & & 635 & (Dunstan et al., 1977)(Philipose et al. \\
\hline & & & \\
\hline & & 652 & (Radoi et al., 2004)(Allen, 1995) \\
\hline & $\left(\mathrm{V}_{\mathrm{Zn}}-\mathrm{V}_{\mathrm{Se}}\right)$ & 730 & (Makhni \& Tkachenko, 2003) \\
\hline & $\left(\mathrm{V}_{\mathrm{Zn}}-\mathrm{Zn}_{\mathrm{i}}\right)$ & 652 & (Makhni \& Tkachenko, 2003) \\
\hline \multirow[t]{3}{*}{$\mathrm{CdSe}$} & $\mathrm{V}_{\mathrm{Cd}}$ & 885 & (Norris, 1982) \\
\hline & $\mathrm{V}_{\mathrm{Se}}$ & 861 & (Pal et al., 2001) \\
\hline & & $704-800$ & (Jager-Waldau et al., 1988) \\
\hline $\mathrm{CdZnSe}$ & & $590-750$ & \\
\hline
\end{tabular}

The values of DL emissions reported in Table 2 are consistent with the observed values (Table 1). Thus, the DL emission is ascribed to a DAP with zinc or selenium vacancy and zinc interstitial. Similarly, the observed dominant emission peak ( 805 $\mathrm{nm}$ ) coincides with the $800 \mathrm{~nm}$ luminescence peak as reported by Rong et al. (Rong \& Watkins, 1986). The peak arises from localized charge transfer or excitonic transition involving Frenkel pairs $\left(\mathrm{V}_{\mathrm{Zn}}-\mathrm{Zn}_{\mathrm{i}}\right)$. The peak at $885 \mathrm{~nm}(1.40 \mathrm{eV})$ was ascribed to cadmium vacancy (Norris, 1982) and is consistent with peak W5 in Table1.

The emission intensities of W2, W3, and W4 show 3.4, 3.3, and a 3.0-fold increase compared with D1, D3, and D4 peaks, respectively. Besides, D1, D3, and D4 peaks show a considerable increase in FWHM values, as shown in Table 2. An increase in PL intensity with decreasing crystallite size (increased milling time) is unpredicted because the concentration of surface state is expected to increase with decreasing crystallite size. Similar observations were already reported [12-14]. The luminescence efficiency $y$ in the nanocrystal can be expressed asn $=\left(1+\beta D^{2}\right)^{-1}$, where $\beta$ is related to the ratio of radiative and non-radiative decay time $\left({ }^{\tau_{R}} / \tau_{N R}\right)$ and $\mathrm{D}$ is the volume of the nanocrystal. Thus, the luminescence efficiency in nanocrystal increases with decreasing crystallite size. Also, PL intensity is linked to improvement in the surface quality of crystallite upon growth mechanism.

The emission in this spectral window is typically associated with deep-level states arising from stacking faults as well as intrinsic point defects such as vacancies and interstitials. In the parent semiconductor $\mathrm{ZnSe}$, the intrinsic point defects reported are the $\mathrm{Zn}$ vacancy $\left(\mathrm{V}_{\mathrm{Zn}}\right), \mathrm{Zn}$ interstitial $\left(\mathrm{Zn}_{\mathrm{i}}\right)$, Se vacancies $\left(\mathrm{V}_{\mathrm{Se}}\right)$, and Se interstitials $\left(\mathrm{Se}_{\mathrm{i}}\right)$ (see Table 2). However, abundant Vse is not expected because of the large formation energy of Vse and the low melting point of Se, resulting in the rapid disappearance of selenium peaks. Furthermore, the observed intrinsic defects are characterized by different charge states and therefore will produce different localized energy levels in the bandgap of the semiconductor. For instance, $\mathrm{V} z \mathrm{n}$ is a double acceptor level with possible charge states of $\mathrm{VZn}^{-}$and $\mathrm{VZn}^{2-}$. Thus, $\mathrm{V}_{\text {se }}$ vacancies and $\mathrm{Zn}_{\mathrm{i}}$ produce states close to the conduction band and will give rise to acceptor states. On the other hand, the produced $\mathrm{V}_{\mathrm{Zn}}$ and $\mathrm{Se}_{\mathrm{i}}$ are donor states near the valance band. The PL emissions of 
DAPs were also reported, where the transition between donors and acceptors leads to additional PL lines (Semenova et al., 2002). The addition of $\mathrm{Cd}$ in $\mathrm{CdZnSe}$ may also produce other intrinsic point defects including $\mathrm{V}_{\mathrm{Cd}}$ and $\mathrm{Cd}_{i}$. However, no current reports were found on the formation of energies and abundances of $\mathrm{V}_{\mathrm{Cd}}$ and $\mathrm{Cd}_{\mathrm{i}}$ in this material.

The number of possible intrinsic defects and DAP transitions can give rise to complex PL spectra with a multitude of peaks. The PL spectra for our samples show a minimum of 6 peaks within the measured spectral window. Interestingly, for the samples milled at 5, 10, and 20h, we identify three PL peaks at $1.8,1.54$, and $1.45 \mathrm{eV}$; the position of the peaks remains constant with milling time. This result is unexpected because the average crystallite diameters reduced with milling time; therefore, the samples milled for longer durations have wider band gaps. A possible explanation is that these PL peaks are associated with electronic transitions from defect levels to the bulk bands. The acceptor defect levels are fixed to the valance band. On the other hand, donor levels have the same features comparable to states in the conduction band that to increase by the energy of the conduction band shift (Oba et al., 2001). Despite the change of band gaps with milling time, the formation energies of acceptor and donor defects remain constant to the conduction and valance band edge. The intensity of these PL peaks increases with milling time because longer milling time corresponds to a higher density of intrinsic defects. A plot of the three PL peaks versus milling time is shown in Fig. 2 below.

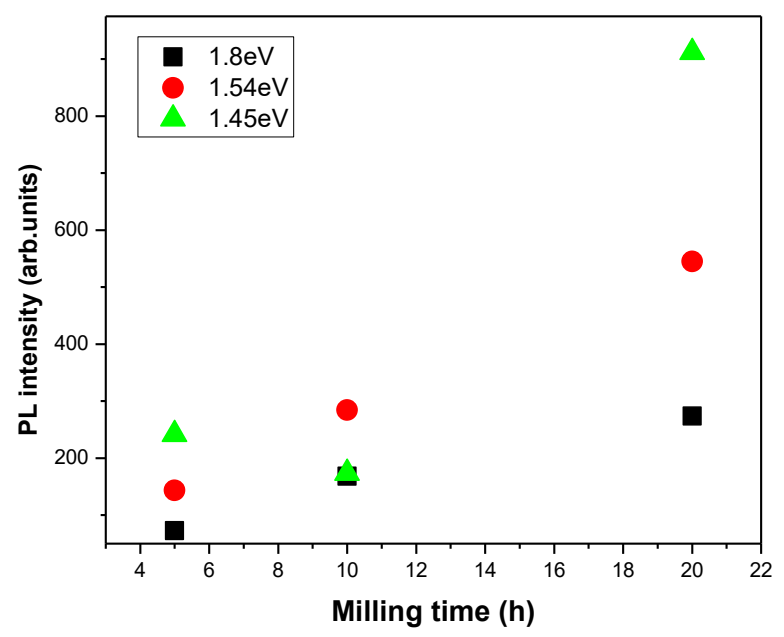

Figure 2. Dependence of PL energy position of different DAP pairs on milling time.

In addition to the three PL peaks, we observe other broadband peaks with a strong dependence on increased milling time (reduced particle diameter). These peaks have the characteristics of the DAP transition. As broadband emission lines, DAP transition energies are dependent on the spatial separation and transition probability of the pairs involved in the recombination process that leads to PL emission. Thus, the spatial distribution of point defects in the nanocrystals can give an enormous number of closely spaced PL lines, leading to a broad DAP line. Additionally, the peak position of DAP lines shifts as the bandgap changes. This phenomenon will lead to a change in the relative energy of the acceptor and donor pairs. The PL energy is given by Equation (1).

$E_{P L} \cong E_{Z n i}(+/ 2+)-E_{V_{z n}}(2-/-)+\frac{e^{2}}{\varepsilon r}+E_{\text {relax }}$

The first terms in the equation represent the energy positions of the donor and acceptor states. On the other hand, the third term donates Coulomb energy, which decreases with $r$; this phenomenon is consistent with the behavior of other peaks in which the energy position of the peaks shifts toward the longer wavelength.

\section{CONCLUSION}

In summary, defect characterization of mechanically alloyed $\mathrm{CdZnSe}$ nanocrystals was conducted using photoluminescence spectroscopy at room temperature. Two prominent emission peaks $(1.4,1.8$, and 1.54) eV were detected in the PL spectrum of 650-900 nm. The peaks remain fixed at a particular energy position without a shift to a higher energy level despite a decrease in particle size of the nanocrystals. We argued that the observed peaks could be due to vacancies and interstitial defects with different charge states $\left(\mathrm{V}_{\mathrm{Cd}}, \mathrm{V}_{\mathrm{Zn}}\right.$, and $\left.\mathrm{V}_{\mathrm{Se}}\right)$ found in the milled samples.

\section{REFERENCE}

Al-Bassam, a. a. I., \& Elani, U. a. (2013). Band Gap and Deep Level of ZnxCd1-xSe Mixed Crystal Cells. Energy Procedia, 32, 216-221. https://doi.org/10.1016/j.egypro.2013.05.028

Allen, J. W. (1995). Spectroscopy of lattice defects in tetrahedral II-VI compounds [Article]. Semiconductor Science and Technology, 10(8), 1049.

Bhattacharyya, S., Estrin, Y., Moshe, O., Rich, D. H., Solovyov, L. A., \& Gedanken, A. (2009). Highly Luminescent Zn x Cd 1$\mathrm{x} \mathrm{Se} / \mathrm{C}$ Core/Shell Nanocrystals: Large Scale Synthesis, Structural and Cathodoluminescence Studies. ACS Nano, 3(7), 1864-1876. https://doi.org/10.1021/nn9005076 
Burger, A., \& Roth, M. (1984). Temperature gradient solution zoning growth and characterization of $\mathrm{ZnxCd} 1-\mathrm{xSe}$ single crystals. Journal of Crystal Growth, 70, 386-392. https://doi.org/10.1016/0022-0248(84)90291-4

Dunstan, D. J., Nicholls, J. E., Cavenett, B. C., Davies, J. J., \& Reddy, K. V. (1977). Optically detected magnetic resonance of the V- centre in ZnSe [JOUR]. Solid State Communications, 24(9), 677-680. https://doi.org/http://dx.doi.org/10.1016/00381098(77)90389-1

Giri, P. K., Bhattacharyya, S., Singh, D. K., Kesavamoorthy, R., Panigrahi, B. K., \& Nair, K. G. M. (2007). Correlation between microstructure and optical properties of $\mathrm{ZnO}$ nanoparticles synthesized by ball milling. Journal of Applied Physics, 102(9), 093515. https://doi.org/10.1063/1.2804012

Jager-Waldau, R., Stucheli, N., Braun, M., Lux Steiner, M., Bucher, E., Tenne, R., Flaisher, H., Kerfin, W., Braun, R., \& Koschel, W. (1988). Thin-film CdSe: Photoluminescence and electronic measurements. Journal of Applied Physics, 64(1988), 2601-2606. https://doi.org/10.1063/1.341649

Lee, K. M., Le Si Dang, \& Watkins, G. D. (1980). OPTICALLY DETECTED MAGNETIC RESONANCE OF THE ZINC VACANCY IN ZnSe. In Solid State Communications (Vol. 35, pp. 527-530). https://doi.org/10.1016/0038-1098(80)90889-3

Makhni, V. P., \& Tkachenko, I. V. (2003). Mechanism for forming the red emission band of $\mathrm{ZnSe}$ scintillation crystals [Article]. J. Opt. Technol., 70(9), 54-57. https://doi.org/10.1364/JOT.70.000665

Muh'd, I. B., Talib, Z. A., Zainal, Z., Chyi, J. L. Y., \& Mofdal, M. E. E. (2015). Mechanochemical solid state synthesis and optical properties of $\mathrm{Cd} 0.5 \mathrm{Zn} 0.5 \mathrm{Se}$ nanocrystals. Journal of Materials $\quad$ Science, $\quad 50(1), \quad 457-462$. https://doi.org/10.1007/s10853-014-8605-5

Norris, C. B. (1982). Cathodoluminescence studies of postrange defect introduction from ion implantation in CdSe. Journal of Applied Physics, 53(1982), 5177-5181. https://doi.org/10.1063/1.331395

Oba, F., Nishitani, S. R., Isotani, S., Adachi, H., \& Tanaka, I. (2001). Energetics of native defects in ZnO. Journal of Applied Physics, 90(2), 824. https://doi.org/10.1063/1.1380994

Pal, U., Muñoz-Avila, S., Prado-González, L., Silva-González, R., \& Gracia-Jiménez, J. . (2001). Effect of laser annealing on the distribution of defect levels in CdSe films. Thin Solid Films, 381(1), 155-159. https://doi.org/10.1016/S00406090(00)01352-3

Philipose, U., Yang, S., Xu, T., \& Ruda, H. E. (2007). Origin of the red luminescence band in photoluminescence spectra of
ZnSe nanowires [Article]. Applied Physics Letters, 90(6). https://doi.org/http://dx.doi.org/10.1063/1.2457190

Radoi, R., de Andrs, M., Fernndez, P., \& Piqueras, J. (2004). Luminescence properties of mechanically milled ZnSe. Physica Status Solidi (A), 201(14), 3183-3187. https://doi.org/10.1002/pssa.200306879

Radoi, R., Fernández, P., Piqueras, J., Wiggins, M. S., \& Solis, J. (2003). Luminescence properties of mechanically milled and laser irradiated ZnO [Article]. Nanotechnology, 14(7), 794.

Rong, F., \& Watkins, G. D. (1986). Observation by Optically Detected Magnetic Resonance of Frenkel Pairs in Irradiated ZnSe [Article]. Physical Review Letters, 56(21), 2310-2313. https://doi.org/10.1103/PhysRevLett.56.2310

Semenova, G. N., Venger, Y. F., Valakh, M. Y., Sadofyev, Y. G., Korsunska, N. O., Strelchuk, V. V, Borkovska, L. V, Papusha, V. P., \& Vuychik, M. V. (2002). Optical investigations of the influence of point defects on quantum dots in $\mathrm{CdSe} / \mathrm{ZnSe}$ heterostructures [Article]. Journal of Physics: Condensed Matter, 14(48), 13375-13380. https://doi.org/10.1088/0953$8984 / 14 / 48 / 391$

Winter, J. O., Gomez, N., Gatzert, S., Schmidt, C. E., \& Korgel, B. A. (2005). Variation of cadmium sulfide nanoparticle size and photoluminescence intensity with altered aqueous synthesis conditions. Colloids and Surfaces A: Physicochemical and Engineering Aspects, 254(1-3), 147-157. https://doi.org/10.1016/j.colsurfa.2004.11.024

Xu, G. Q., Liu, B., Xu, S. J., Chew, C. H., Chua, S. J., \& Gana, L. M. (2000). Luminescence studies of CdS spherical particles via hydrothermal synthesis. Journal of Physics and Chemistry of Solids, 61(6), 829-836. https://doi.org/10.1016/S00223697(99)00403-5

Yua, I., Isobe, T., Senna, M., \& Takahashi, S. (1996). Optical properties and characteristics of $\mathrm{ZnS}$ nano- particles with homogeneous Mn distribution. 38(4), 177-181. https://doi.org/http://dx.doi.org/10.1016/0921-5107(95)014454

Zhang, X. B., \& Hark, S. K. (2000). Influence of gas flow stoichiometry on the luminescence of organometallic-vaporphase-grown $\mathrm{Zn}[\mathrm{sub} \mathrm{x}] \mathrm{Cd}[\mathrm{sub} 1-\mathrm{x}] \mathrm{Se}$ epilayers. Applied Physics Letters, 76(2000), 1674. https://doi.org/10.1063/1.126132

Zhang, X. B., Won, H. K., \& Hark, S. K. (1998). Depth-resolved cathodoluminescence study of Zn-x Cd1-xSe epilayer grown on (001) InP by metal organic chemical vapor phase deposition. Applied Physics Letters, 73(001), 3238-3240. https://doi.org/Doi 10.1063/1.122730. 